\title{
Seismic-Resistant Investigation of Multi-Storey Building by Response Spectrum Method
}

\author{
Shankha Pratim Bhattacharya \\ Department of Architecture, Birla Institute of Technology, Mesra, Ranchi-835215, Jharkhand, India
}

\author{
Swapan Kumar Chakraborty \\ Department of Applied Mathematics, Birla Institute of Technology, Mesra, Ranchi-835215, Jharkhand, India
}

(Received 2 July 2009; revised 3 November 2009; accepted 8 July 2010)

\begin{abstract}
The present article attempts to evaluate the earthquake resistance of a four-storey building frame. It also compares the performance of buildings with soft ground floors and different infill parameters, such as brick wall and shear wall. The Indian standard code (IS-code) of practice (IS: 1893, Part-1:2002) guidelines and methodology are used to analyze the problem. Response spectrum method, involving various modal participations, is employed to evaluate the nodal forces in the typical beam-column junctions. The frame members, infill walls and floors are tackled as rigid end joints, panel element, and diaphragms rigid in-plane, respectively. Linear elastic analysis is performed with individual floor mass and stiffness, taking into account the building as a multiple degrees of freedom system. The effect of damping and the soil criteria are also studied as per the provision of IS-code. The investigation concludes that the proper mass and stiffness distribution in multi-storied buildings will minimize the hazardous effects of seismic excitation. The mathematical model of the building finally recognized the hazardous features of Indian reinforced concrete buildings and recommends some measures to improve the seismic performance.
\end{abstract}

\section{NOMENCLATURE}

\begin{tabular}{|c|c|}
\hline$A$ & arbitrary constant \\
\hline$A_{c}$ & area of equivalent diagonal strut \\
\hline$\left(A_{h}\right)_{j}$ & design acceleration spectrum for the $j^{t h}$ mode \\
\hline$E_{m}$ & elastic modulus of infill masonry \\
\hline$[F]$ & force vector \\
\hline$K_{i}$ & $i^{t h}$ storey stiffness \\
\hline$[K]$ & stiffness matrix \\
\hline$K_{w}$ & stiffness of the infill wall \\
\hline$L_{d}$ & length of diagonal strut \\
\hline$[M]$ & mass matrix \\
\hline$p_{j}$ & modal participation factor for the $j^{t h}$ mode \\
\hline$Q_{i j}$ & $\begin{array}{l}\text { design lateral force at the } i^{t h} \text { floor and the } j^{t h} \\
\text { mode }\end{array}$ \\
\hline$V_{i j}$ & storey shear force at the $i^{t h}$ floor and the $j^{t h}$ mode \\
\hline$\nu_{i}$ & peak storey shear force \\
\hline$W_{i}$ & weight of the $i^{t h}$ floor of the building \\
\hline$[\ddot{X}]$ & acceleration vector \\
\hline$[X]$ & displacement vector \\
\hline$x(t)$ & time variant displacement \\
\hline$\omega$ & circular frequency of the vibration \\
\hline$\left(\varphi_{i j}\right)$ & $\begin{array}{l}\text { mode shape coefficient at the } i^{t h} \text { floor and the } j^{t h} \\
\text { mode }\end{array}$ \\
\hline$\varphi_{i}$ & $i^{t h}$ eigenvalue or mode shape \\
\hline$\theta$ & slope of the diagonal strut \\
\hline$\Delta_{i}$ & storey drift at the $i^{t h}$ floor \\
\hline
\end{tabular}

\section{INTRODUCTION}

Earthquakes are a constant source of both fascination and horror. The deaths and loss of property during earthquakes are caused by the collapse of buildings. In the process of architectural design, it is a common practice to make major and minor adjustments to create habitable space formation. Rational studies and the knowledge regarding the performance of building structures during earthquake excitation show that maladjustments decrease the seismic-resistance capacity of the structure and lead to the collapse of the building. An integral seismic-resistant building system, in which all the components of the building's structure can effectively interact during the seismic action, is utterly necessary. Several studies and various recommendations from different building codes have been carried out to minimize the damage of the structures due to earthquakes. The Bhuj earthquake, which occurred in India in January 2001, left thousands of people dead or injured, was representative of an inadequacy in seismic-resistive structural system. On the other extreme, an earthquake near Olympia, Washington, had a comparable magnitude but resulted in only minor injuries that numbered in the hundreds. While there was extensive damage to structures during the Olympia earthquake, no devastation was reported. ${ }^{1}$ The difference in outcomes from these two earthquakes can be attributed to the use of seismicresistant design techniques.

An overall regularity in building configuration, mass, and the stiffness distribution are considered to be the basics feature of earthquake resistant buildings. The eleven-storey Manasi Apartments in Ahmedabad, India, collapsed due to the inverted pendulum effect during the 2001 earthquake. The weight of the swimming pool and reservoir a top the building contributed to the severity of the damage. ${ }^{2}$ Mezzi et al. investigated the fundamental issue of the structural configuration of buildings with various load-resisting frames and peak ground acceleration. ${ }^{3}$ 